\title{
Visceral obesity in the normal-weight people-comparing chronic schizophrenia and healthy control subjects
}

\author{
Siew Yim Loh ${ }^{1 *}$, Amirah Yusof ${ }^{1}$ and Abdul Kadir Abu Bakar ${ }^{2}$ \\ ${ }^{1}$ Department of Rehabilitation Medicine, Faculty of Medicine, University of Malaya Kuala Lumpur. Malaysia \\ ${ }^{2}$ Hospital Permai, Johor Bahru, Malaysia
}

\begin{abstract}
Background: People living with Schizophrenia are often associated with obesity due to a fairly sedentary lifestyle. However, there are less study findings about body composition of normal weight chronic schizophrenia inmates. The aim of this study is to compare body composition variables between normal weight chronic schizophrenia inmates and age-gender matched healthy control subjects in Malaysia.

Methods: People with chronic schizophrenia, based on DSM-IV, and with normal weight were recruited from the pool of patients in a large hospital. Body fat percentage $(\%)$, Body fat mass $(\mathrm{kg})$, fat free mass $(\mathrm{kg})$, body muscle mass $(\mathrm{kg})$, visceral fat rating and total body water were measured using bioelectrical impedance analysis (BIA) method. Comparative analysis was performed between the normal BMI schizophrenia inmates and healthy control subjects.

Results: There were 247 consented subjects with normal BMI (164 males and 83 females). Their age range between 18-91 years old (mean/SD=58+13.17) were compared to 64 normal weight healthy controls ( 25 males and 39 females (mean/SD=34 \pm 10.87 ) years old; age range of $21-58$ years old. Among males, fat free mass and body muscle mass are significantly higher in normal BMI healthy control subjects compared to chronic schizophrenia inmates ( $\mathrm{p}$-value $<0.05$ ). Among females, fat free mass and body muscle mass are significantly higher in normal BMI healthy control subjects compared to chronic schizophrenia inmates. Meanwhile, visceral fat rating is significantly higher in normal BMI chronic schizophrenia inmates than healthy controls for both males and females with Mean \pm SD $(8 \pm 2.91$ and $7 \pm$ 1.58) respectively. Age, weight, were significant for the schizophrenic inmates (both gender), whist only BMI was significantly higher in male healthy control subjects $(\mathrm{p}<0.05)$
\end{abstract}

Conclusions: The findings show that normal BMI schizophrenia patients have higher visceral fat rating and lower fat free mass and body muscle mass compared to healthy controls. In addition, the longer the duration of illness the higher the visceral fat rating among the inmates. These results indicate that community rehabilitation program should be individualised even for Chronic Schizophrenia with normal BMI, to ensure better health and wellbeing.

\section{Introduction}

Schizophrenia is a chronic debilitating psychotic mental illness that affect about one percent of people in the world presenting with the symptoms of hallucination and delusion [1]. Among schizophrenia patients, they are highly related to obesity due to several factors such as antipsychotic medication [2], physical inactivity [3,4] and poor dietary intake $[5,6]$. Obesity is a well-known global burden on health and to make it worst the number tend to increase from year to year and Malaysia as a developing country is not excluded from having the same problem [7]. Meanwhile, in general population, the overall prevalence of obesity of Malaysian adults was $19.5 \%$ (from 4341 adults) which is higher that the prevalence reported by National Health and Morbidity Survey (NHMS III) in 2006 which was $14 \%$ [7-9]. The increase in obesity is worrying as it can increase the development of metabolic syndrome such as cardiovascular disease (CVD), type 2 diabetes mellitus [10,11] hypertension [12].

Recent studies suggested that even people who are not in obese BMI category, can be presented with high fat readings. The study done by Konarzewska et al. [13] documented that normal BMI schizophrenia patients have significantly higher visceral-fat ratio compared to healthy control. Bioelectrical Impedance method (BIA) has been used to measure body composition i.e. body fat, fat free mass, body muscle mass, visceral fat and total body water of an individual [14], based on the concept of resistance and electric current passing through the tissue containing fluids, electrolytes and lipid. Thus, body with high lipid proportion will definitely increase the electric current resistance and result in higher fat reading from the BIA [15]. Study done by Sharpe et al. [16] comparing the reading of body fat using BMI and Body Impedance analysis (BIA) show that the correlation of BIA and percentage of body fat is nearly twice compared to the correlation between BMI and body fat percentage. This proves that BIA method is more practical in determining the level of adiposity of the body. In addition, from the same study, 9 out of 15 overweight subjects is categorized as obese based on BIA measurement that give a result of

Correspondence to: Siew Yim Loh, Department of Rehabilitation Medicine, Faculty of Medicine, University of Malaya, Kuala Lumpur, Malaysia, E-mail: syloh@um.edu.my

Key words: ody composition, normal weight chronic schizophrenia, visceral fat rating, healthy control subjects, BMI

Received: August 10, 2017; Accepted: August 15, 2017; Published: August 18, 2017 
body fat percentage $>30 \%$. BMI reading is often associated with level of muscularity instead of adiposity [16]. Bigard et al. [17] suggested that in determining body composition of an individual, additional parameter such as BIA measurement should be an additional option. This is to avoid excess accumulation of fat due to the escape detection of metabolic syndrome just because some individuals have a normal BMI reading.

As recommended by World Health Organization, the group of BMI are categorized as $<18.5 \mathrm{~kg} / \mathrm{m}^{2}$ (Underweight), $18.5 \mathrm{~kg} / \mathrm{m}^{2}$ to $24.9 \mathrm{~kg} / \mathrm{m}^{2}$ (Normal weight), $25 \mathrm{~kg} / \mathrm{m}^{2}$ to $29.9 \mathrm{~kg} / \mathrm{m}^{2}$ (Overweight) and $>30 \mathrm{~kg} / \mathrm{m}^{2}$ (Obese) [18]. However, there are many more terms regarding weight that has been used. Individual with a normal BMI reading that is between $18.5 \mathrm{~kg} / \mathrm{m}^{2}$ and $24.9 \mathrm{~kg} / \mathrm{m}^{2}$ and high body fat percentage $(>30 \%)$ is defined as normal weight obesity individuals [19]. Meanwhile, Rutherman et al. [20] has suggested the term metabolically obese, normal weight (MONW) individuals which represent those who are not obese (BMI $\left.18.5 \mathrm{~kg} / \mathrm{m}^{2}-24.9 \mathrm{~kg} / \mathrm{m}^{2}\right)$ and has a risk factors in developing metabolic syndrome such as type 2 diabetes mellitus, hyperlipidemia and coronary heart disease. It is well known that diet intake is associated with the causes of physical illness and there is little research that associate diet intake with mental illness [21]. Therefore, many study has been done in order to assess dietary intake of schizophrenia patients. In a study by Amani [22] reported that majority of the male patient consumed high fat food such as hydrogenated fats and full cream milk daily as Iranian main food are prepared from hydrogenated fats (ghee). In addition, study done by Henderson et al [23] suggested that both the schizophrenia and the control group consume similar percentage of macronutrients (Carbohydrate, protein and fat). However, schizophrenia group consume less energy than the control group and the quality of their diet is quite poor as the fiber intake is less than the recommendation. Whereas, finding by Peet [21] showed that schizophrenia patient consumes high intake of refined sugar, meat and eggs, which lead to adverse outcome of schizophrenia syndrome. In study done by Sharp et al. [16] suggested that despite the large amount of food consume by schizophrenia patient that is approximately 4500 $\mathrm{kcal} /$ day, they still did not gain weight, possibly due to the indigestion, malabsorption or metabolism issues of chronic schizophrenia patients. The main objectives of this study were to compare body composition variables between normal weight chronic schizophrenia patients and healthy control. The second objective is to see the association between duration of illness and body composition variables. We hypothesized that the longer the duration of illness suffered by patients, the higher the reading of body fat and visceral fat rating.

\section{Methods}

\section{Participants}

The subjects were 247 normal BMI chronic schizophrenia inmates (mean \pm SD $21.5 \pm 1.82 \mathrm{~kg} / \mathrm{m}^{2} ; 164$ males and 83 females) treated in Permai Hospital, Johor Baharu who were diagnosed with chronic schizophrenia with mean duration of $(24 \pm 14.78$ years $)$ based on the DSM-IV diagnostic criteria. As a reference group, 64 normal BMI healthy individuals (mean \pm SD $22.5 \pm 1.96 \mathrm{~kg} / \mathrm{m}^{2} ; 25$ males and 39 females) were also included. Inclusion criteria include normal BMI from a larger database for schiz health study and presented with no complication of metabolic syndrome. Exclusion criteria included acute schizophrenia, schizophrenia with other medical problems and transitional ward.

\section{Data Collection Procedure}

Information on subject's demographic data (age, sex, ethnicity and education level) was obtained from their medical records.
Anthropometry measurement including height and weight were determined without wearing shoes, using standard procedure. Body composition was measured using BIA machine (Tanita 312). The measurement procedure required the subjects to stand barefooted on the BIA machine and to hold a pair of handgrips, one in each hand. The results of body fat percentage, body fat mass, fat free mass, body muscle mass, visceral fat rating and total body water were calculated by the machine.

\section{Data analysis}

The data were checked for normality this study is based on data collected for a larger study. Descriptive statistical analyses were performed to describe the demographic data and clinical characteristics. To compare the main demographic and clinical characteristic between patient and control, an independent t-test was performed to analyse continuous variables. Data was normally distributed. Data are presented as mean \pm SD. ANOVA was conducted to examine for statistical difference between body compositions in the 3 duration-of-illness groups. Multiple linear regression analysis was employed to analyse the continuous variables of body composition. The Independent variables were Age, gender, duration of illness and BMI). The data were analyse using SPSS version 21.0.

\section{Result}

\section{Demographic characteristics}

The characteristics of participants are listed in Table 1. Among males, age is significantly higher in normal BMI schizophrenia inmates (mean \pm SD 55 years old \pm 13.18 ) than in healthy control. Meanwhile, weight and BMI is significantly higher in normal BMI healthy individual (Mean \pm SD $64 \mathrm{~kg} \pm 6.53$ and $23.0 \pm 1.83 \mathrm{~kg} / \mathrm{m}^{2}$ respectively) compared to schizophrenia inmates. In females, age is significantly higher in normal BMI schizophrenia inmates (mean \pm SD 62 years old \pm 11.79 ) than healthy individuals. Body weight and height are significantly higher in healthy control subjects (Mean \pm SD $54.3 \mathrm{~kg} \pm 4.91$ and $157 \mathrm{~cm}$ \pm 5.96 respectively) compared to schizophrenia inmates.

\section{Body composition measurement}

Table 2 shows the body composition measurement of normalBMI inmates with chronic schizophrenia and normal-BMI healthy control subjects. Among males, fat free mass and body muscle mass are significantly higher in normal BMI healthy control subjects (Mean \pm SD $51.8 \pm 4.64$ and $49.1 \pm 4.51$ respectively) compared to chronic schizophrenia inmates $(\mathrm{p}<0.05)$. Meanwhile, visceral fat rating is significantly higher in normal BMI chronic schizophrenia inmates (Mean \pm SD $8 \pm 2.91$ ) than healthy controls. Among females, fat free mass and body muscle mass are significantly higher in normal BMI healthy control subjects (Mean \pm SD $37.2 \pm 2.94$ and $22.2 \pm 2.01$ respectively) compared to chronic schizophrenia inmates. Meanwhile, visceral fat rating is significantly higher in normal BMI chronic schizophrenia inmates (Mean \pm SD $7 \pm 1.58$ ) than healthy controls.

\section{Body composition measurements according to duration of illness}

Table 3 shows the three-group's duration of illness and body composition measurement. The duration of illness of these normal BMI inmates $(\mathrm{n}=247)$ with a mean of $24 \pm 14.8($ Mean \pm SD) years were categorised as $<20$ years $(n=117), 20-40$ years $(n=88)$, $>40$ years $(n=42)$. Fat free mass and body muscle mass of the inmates with duration of illness $<20$ years is significantly higher compared to other groups with $44.1 \pm 7.54$ and 41.8 $\pm 7.19($ Mean $\pm S D)$ respectively. Meanwhile, visceral 
Table 1. Study groups characteristics of chronic schizophrenia patient $(n=247)$ compared to healthy control subjects $(n=64)$.

\begin{tabular}{|c|c|c|c|c|c|c|}
\hline & \multicolumn{3}{|c|}{ Male } & \multicolumn{3}{|c|}{ Female } \\
\hline & Schizophrenia & Control & \multirow{2}{*}{ p-value } & Schizophrenia & Control & \multirow{2}{*}{ p-value } \\
\hline & $(\mathrm{n}=164)$ & $(\mathrm{n}=25)$ & & $(\mathrm{n}=83)$ & $(\mathrm{n}=39)$ & \\
\hline Age (Years) & $55 \pm 13.18$ & $35 \pm 11.21$ & $<0.05$ & $62 \pm 11.79$ & $33 \pm 10.72$ & $<0.05$ \\
\hline Body weight $(\mathrm{kg})$ & $58 \pm 7.21$ & $64 \pm 6.53$ & $<0.05$ & $50.2 \pm 5.93$ & $54.3 \pm 4.91$ & $<0.05$ \\
\hline Height $(\mathrm{cm})$ & $164 \pm 7.32$ & $167 \pm 6.05$ & 0.081 & $151 \pm 6.48$ & $157 \pm 5.96$ & $<0.05$ \\
\hline BMI & $21.3 \pm 1.86$ & $23.0 \pm 1.83$ & $<0.05$ & $21.9 \pm 1.69$ & $22.2 \pm 2.01$ & 0.426 \\
\hline
\end{tabular}

Table 2. Body composition measurement of chronic schizophrenia inmates $(n=247)$ and healthy control subjects $(n=64)$

\begin{tabular}{|c|c|c|c|c|c|c|}
\hline & \multicolumn{3}{|c|}{ Male } & \multicolumn{3}{|c|}{ Female } \\
\hline & Schizophrenia & Control & \multirow{2}{*}{ p-value } & Schizophrenia & Control & \multirow{2}{*}{ p-value } \\
\hline & $(n=164)$ & $(\mathrm{n}=25)$ & & $(\mathrm{n}=83)$ & $(\mathrm{n}=39)$ & \\
\hline Body Fat percentage (\%) & $19.5 \pm 4.49$ & $18.8 \pm 3.60$ & 0.501 & $32.2 \pm 4.17$ & $31.6 \pm 4.06$ & 0.482 \\
\hline Body fat mass (kg) & $11.3 \pm 3.32$ & $12.2 \pm 2.97$ & 0.224 & $16.3 \pm 3.31$ & $17.4 \pm 3.27$ & 0.105 \\
\hline Fat free mass (kg) & $46.2 \pm 5.40$ & $51.8 \pm 4.64$ & $<0.05$ & $34.0 \pm 3.68$ & $37.2 \pm 2.94$ & $<0.05$ \\
\hline Body muscle mass $(\mathrm{kg})$ & $43.8 \pm 5.15$ & $49.1 \pm 4.51$ & $<0.05$ & $21.9 \pm 1.69$ & $22.2 \pm 2.01$ & $<0.05$ \\
\hline Visceral fat rating & $8 \pm 2.91$ & $5 \pm 2.58$ & $<0.05$ & $7 \pm 1.58$ & $4 \pm 1.83$ & $<0.05$ \\
\hline Total body water (\%) & $55.1 \pm 4.72$ & $55.3 \pm 3.48$ & 0.853 & $48.9 \pm 3.91$ & $47.8 \pm 2.62$ & 0.122 \\
\hline
\end{tabular}

Table 3. Duration of illness and body composition of normal BMI chronic schizophrenia inmates $(\mathrm{n}=247)$ and healthy control subjects $(\mathrm{n}=64)$

\begin{tabular}{|c|c|c|c|c|}
\hline & $\begin{array}{c}<20 \text { years } \\
(n=117)\end{array}$ & $\begin{array}{c}\text { 20-40 years } \\
(\mathrm{n}=88)\end{array}$ & $\begin{array}{c}>40 \text { years } \\
\quad(n=42)\end{array}$ & p-value \\
\hline \multirow{2}{*}{\begin{tabular}{|c|} 
Body Fat \\
Percentage (\%)
\end{tabular}} & $23.6 \pm 7.64$ & $23.3 \pm 7.49$ & $25.3 \pm 6.68$ & \\
\hline & (Range: 5-39) & (Range: 10-40) & (Range: 12-36) & 0.327 \\
\hline \multirow{2}{*}{$\begin{array}{c}\text { Body fat mass } \\
(\mathrm{kg})\end{array}$} & $13.5 \pm 4.27$ & $12.4 \pm 3.97$ & $13.0 \pm 3.51$ & \multirow{2}{*}{0.148} \\
\hline & (Range: 3-22) & (Range: 6-24) & (Range: 6-20) & \\
\hline \multirow{2}{*}{$\begin{array}{l}\text { Fat Free Mass } \\
(\mathrm{kg})\end{array}$} & $44.1 \pm 7.54$ & $41.2 \pm 7.01$ & $38.5 \pm 5.39$ & \multirow{2}{*}{$<0.001$} \\
\hline & (Range: 26-59) & (Range: 26-60) & (Range: 28-48) & \\
\hline \multirow{2}{*}{$\begin{array}{l}\text { Body muscle } \\
\text { mass }(\mathrm{kg})\end{array}$} & $41.8 \pm 7.19$ & $39.1 \pm 7.35$ & $36.5 \pm 5.16$ & \multirow{2}{*}{$<0.001$} \\
\hline & (Range: 25-56) & (Range: 25-57) & (Range: 26-46) & \\
\hline \multirow{2}{*}{$\begin{array}{l}\text { Visceral fat } \\
\text { rating }\end{array}$} & $7 \pm 2.44$ & $8 \pm 2.40$ & $10 \pm 2.39$ & \multirow{2}{*}{$<0.001$} \\
\hline & (Range: 2-14) & (Range: 4-16) & (Range: 4-14) & \\
\hline \multirow{2}{*}{$\begin{array}{c}\text { Total body water } \\
(\%)\end{array}$} & $52.6 \pm 5.56$ & $53.9 \pm 5.36$ & $52.2 \pm 4.56$ & \multirow{2}{*}{0.132} \\
\hline & (Range: 41-72) & (Range: 41-66) & (Range: 44-64) & \\
\hline
\end{tabular}

fat rating is significantly higher in inmates with duration of illness $>40$ years $10 \pm 2.39$ (Mean $\pm \mathrm{SD}$ ).

Multiple regression analysis for the detailed body composition characteristics.

Table 4 shows the regression analysis within the normal weight schizophrenia inmates to determine the association between duration of illness and body composition. Shorter duration of illness is significantly associated with higher fat free mass and body muscle mass ( $p<0.05, r^{2}=0.731$ ). Longer duration of illness among normal BMI chronic schizophrenia inmates is associated with higher visceral fat rating (Figure 1).

\section{Discussion}

The present study on the body composition of patients diagnosed with chronic schizophrenia is the first to compare with healthycontrol subjects in Malaysia. The main findings of this study were that both normal weight healthy controls had fat free mass and body muscle mass significantly higher than that of chronic schizophrenia patients. However, there is no significant difference with respect to body fat percentage and body fat mass in both genders of both subjects. Meanwhile, both normal weight male and female chronic schizophrenia patient had a significantly higher visceral fat rating compared to healthy control subjects.
Table 4. Multiple regression analysis for the detailed body composition characteristics of normal weight schizophrenia inmates $(n=247)$

\begin{tabular}{|c|c|c|c|}
\hline \multirow{5}{*}{$\begin{array}{l}\text { Body fat percentage } \\
(\%)\end{array}$} & & Beta coefficient & p-value \\
\hline & Gender & -11.4 & $<0.05$ \\
\hline & Age & 0.873 & $<0.05$ \\
\hline & Duration of illness & 0.517 & 0.15 \\
\hline & BMI & 1.527 & $<0.05$ \\
\hline \multirow{4}{*}{ Body fat mass (kg) } & Gender & -4.104 & $<0.05$ \\
\hline & Age & 0.056 & 0.829 \\
\hline & Duration of illness & -0.002 & 0.993 \\
\hline & BMI & 1.388 & $<0.05$ \\
\hline \multirow{4}{*}{ Fat free mass $(\mathrm{kg})$} & Gender & 11.867 & $<0.05$ \\
\hline & Age & -2.296 & $<0.05$ \\
\hline & Duration of illness & -0.902 & $<0.05$ \\
\hline & BMI & 1.025 & $<0.05$ \\
\hline \multirow{4}{*}{$\begin{array}{l}\text { Body muscle mass } \\
(\mathrm{kg})\end{array}$} & Gender & 11.314 & 0.05 \\
\hline & Age & -2.244 & $<0.05$ \\
\hline & Duration of illness & -0.811 & $<0.05$ \\
\hline & BMI & 0.979 & $<0.05$ \\
\hline \multirow{4}{*}{ Visceral fat rating } & Gender & 3.119 & $<0.05$ \\
\hline & Age & 2.669 & $<0.05$ \\
\hline & Duration of illness & 0.54 & $<0.05$ \\
\hline & BMI & 0.628 & $<0.05$ \\
\hline \multirow{4}{*}{ Total body water (\%) } & Gender & 5.876 & $<0.05$ \\
\hline & Age & 0.451 & 0.361 \\
\hline & Duration of illness & -0.342 & 0.43 \\
\hline & BMI & -0.895 & $<0.05$ \\
\hline
\end{tabular}

Previous studies have compared the body composition of chronic schizophrenia patients with healthy control subjects. Study by Nillson et al. [24] on 28 schizophrenia patients and 17 healthy control subjects showed that body-fat percentage and body-fat mass in schizophrenia patients were significantly higher than healthy-control subjects. Meanwhile, Saarni et al. [25] suggested that schizophrenia patients $(n=58)$ was associated with significantly greater fat percentage and lower fat free mass when age, gender and BMI were controlled. According to Sugawara et al. [26], males schizophrenia patients had a significantly higher body fat percentage and body fat mass compared to healthy controls, hence fat free mass and body muscle mass were significantly higher in healthy controls. In females, schizophrenia patients had significantly higher body fat percentage, fat free mass, body muscle mass and total body water than healthy controls. Furthermore, Konarzewska 


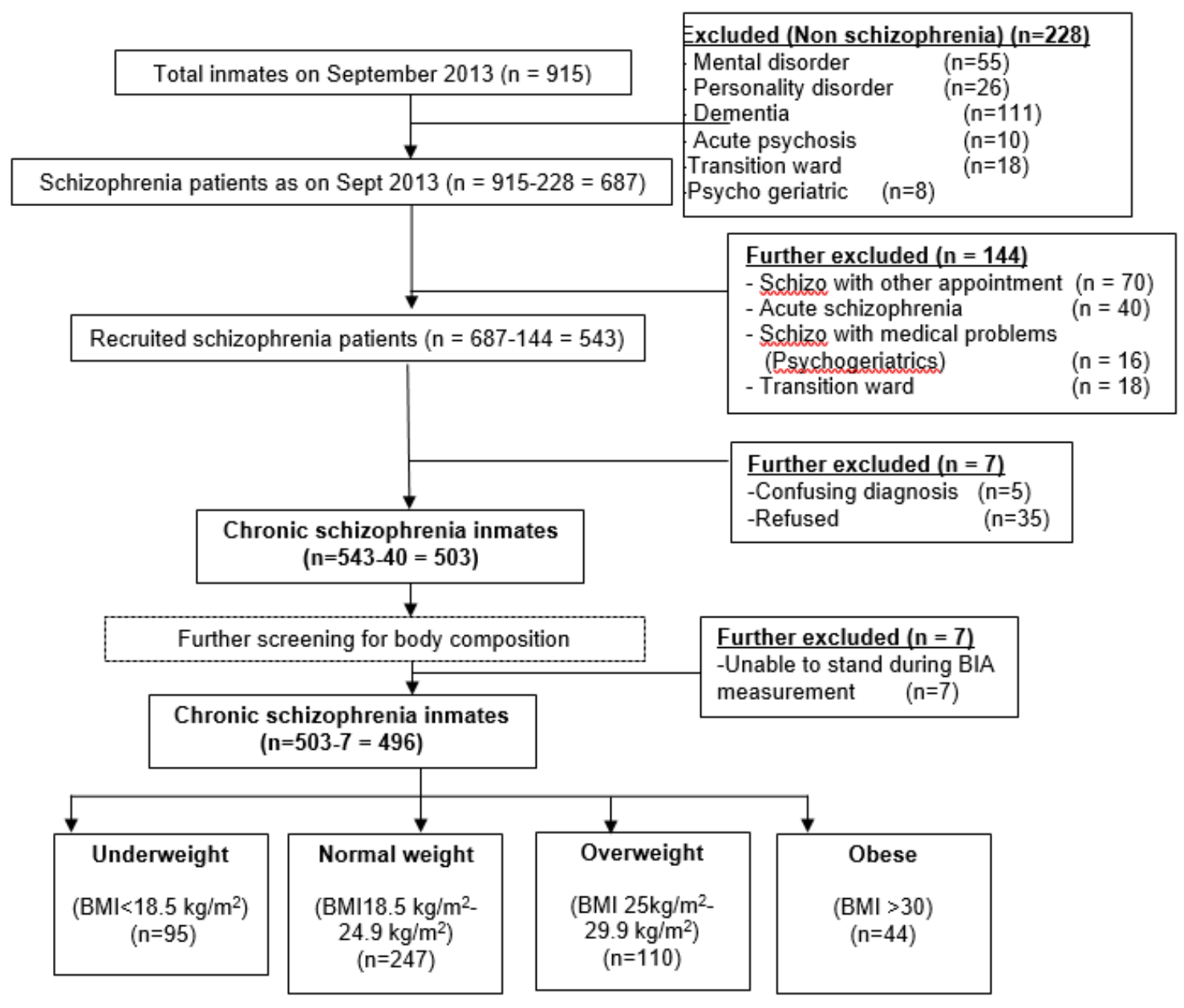

Figure 1. Process of recruitment of the subjects

et al. [13] reported that among males subjects, healthy controls had significantly higher fat free mass compared to schizophrenia patients.

Obesity is well known for its adverse effects in health and many interventions and prevention has been made in this group of individuals. However, Ruderman et al. [20] has suggested another group of individuals known as metabolically obese normal weight (MONW) which characterized as individual having normal weight (BMI between $18.5-24.9 \mathrm{~kg} / \mathrm{m}^{2}$ ) but demonstrate insulin resistance and various metabolic consequences which may lead to development serious medical condition such as type 2 diabetes mellitus, coronary heart disease and early death. To make it worst, since they are not overweight or obese, they are being escape from early detection and prevention of health co morbidities.

The higher visceral fat rating among male schizophrenia patients raised concern as visceral fat has a higher lipolytic activity and directly release free fatty acid (FFA) into portal circulation and lead to insulin resistance [27]. One of the factors that contribute to a high visceral fat distribution among schizophrenia patients is the level of cortisol in the body. According to the study done by Thakore et al. [28], reported that schizophrenia patient had higher plasma cortisol level compared to healthy control. Therefore, high level of plasma cortisol results in the increase of lipoprotein lipase (LPL) which is the primary enzyme responsible for the deposition of visceral fat in the body and high cortisol level also inhibits lipid mobilization [29-31]. According to Garaulet et al. [32], body fat distribution is different respective to gender (since women have less visceral fat but more subcutaneous fat compared to men). Another study showed that male schizophrenia patients have higher visceral fat and female schizophrenia patients have higher body fat percentage and higher body fat mass readings. Garaulet et al. [32] suggested that these differences might be due to sex hormones. In women, oestrogen increases the subcutaneous fat deposition by increasing insulin sensitivity. This then reduces the accumulation of triglyceride in the visceral adipose tissue [33]. Meanwhile, testosterone in men inhibit tryglyceride uptake and LPL activity has cause the accumulation of lipid in the visceral adipose tissue which explained that men has a higher visceral fat rating compared to women [34]. Meanwhile, a large prospective study by Vogelzangs et al. [35] suggested that individual with depression symptoms tend to have a higher visceral fat rating compared to those without the symptoms although the depressed individual lose weight and they still presented with a high visceral fat rating. In addition, depressive symptoms were significantly associated with accumulation of fat at the visceral region.

The significant association between duration of illness with fat free mass, body muscle mass and visceral fat rating suggested that this may be due to antipsychotic medication and physical inactivity [13]. Study done by Slentz et al. [36] in subjects that involved in doing physical activities ranging from moderate intensity (Walking12 miles/week) to highly vigorous intensity (Jogging 20 miles/week) reported that there 
are decreased in the amount of subcutaneous fat and visceral fat. From our finding, shorter duration of illness is associated with higher fat free mass and body muscle mass. While longer duration of illness is associated with higher visceral fat rating.

This can be concluded that the longer the duration of illness, the likelihood of adopting a more sedentary lifestyle becomes the norm of these patients living within a confined institution. In addition, the association between duration of illness and high visceral fat rating might be contributed by long term prescription of antipsychotic medication. According to Zhang et al. [37], antipsychotic medication induces abdominal fat distribution and hyperlipidemia.

\section{Conclusion}

This study has shown that both male and female schizophrenia patients had more body fat and lower fat free mass and body muscle mass compared to healthy controls. Meanwhile, male patients had higher visceral fat rating compared to other subjects. Although this study only takes into account the body composition without assessing the physical activity and prescribed medication of the patient, we suggest that the lifestyle habits of the patients to be modified in order to improve their body composition and to prevent other health comorbidities. Further research can be done in assessing diet intake of the patient in order to determine the exact factors that contribute to the high reading of body fat among schizophrenia patients.

\section{Acknowledgement}

The study was partially funded by The SchizHealth HIR Project, University of Malaya.

\section{References}

1. Freedman R (2003) Schizophrenia. N Engl J Med 349: 1738-1749. [Crossref]

2. Ryan MC, Flanagan S, Kinsella U, Keeling F, Thakore JH (2004) The effects of atypical antipsychotics on visceral fat distribution in first episode, drug-naïve patients with schizophrenia. Life Sci 74: 1999-2008. [Crossref]

3. Ussher M, Stanbury L, Cheeseman V, Faulkner G (2007) Physical activity preferences and perceived barriers to activity among persons with severe mental illness in the United Kingdom. Psychiatr Serv 58: 405-408. [Crossref]

4. Stubbs B, Williams J, Gaughran F, Craig T (2016) How sedentary are people with psychosis? A systematic review and meta-analysis. Schizophr Res 171: 103-109. [Crossref]

5. McCreadie RG; Scottish Schizophrenia Lifestyle Group (2003) Diet, smoking and cardiovascular risk in people with schizophrenia: descriptive study. $\mathrm{Br} J$ Psychiatry 183: 534-539. [Crossref]

6. Dipasquale S, Pariante CM, Dazzan P, Aguglia E, McGuire P, et al. (2013) The dietary pattern of patients with schizophrenia: a systematic review. J Psychiatr Res 47: 197207. [Crossref]

7. Wan Nazaimoon WM, Md Isa SH, Wan Mohamad WB, Khir AS, Kamaruddin NA, et al. (2013) Prevalence of diabetes in Malaysia and usefulness of HbA1c as a diagnostic criterion. Diabet Med 30: 825-828. [Crossref]

8. Norlelawati A, Kartini A, Ramli M, Norsidah K, Wan Azizi, et al. (2012) Obesity in multiracial schizophrenia patients receiving outpatient treatment in a regional tertiary hospital in Malaysia. East Asian Arch Psychiatry 22: 49. [Crossref]

9. Institute for Public Health (IPH) (2008) The Third National Health and Morbidity Survey (NHMS III), Nutritional Status. Ministry of Health, Malaysia.

10. Yusuf S, Hawken S, Ounpuu S, Bautista L, Franzosi MG, et al. (2005) Obesity and the risk of myocardial infarction in 27,000 participants from 52 countries: a case-control study. Lancet 366: 1640-1649. [Crossref]

11. Meyer JM, Stahl SM (2009) The metabolic syndrome and schizophrenia. Acta Psychiatr Scand 119: 4-14. [Crossref]
12. Grundy SM, Cleeman JI, Daniels SR, Donato KA, Eckel RH, et al. (2005) Diagnosis and management of the metabolic syndrome an American Heart Association/National Heart, Lung, and Blood Institute scientific statement. Circulation 112: 2735-2752. [Crossref]

13. Konarzewska B, Stefazska E, Wendozowicz A, Cwalina U, Golonko A, et al. (2014) Visceral obesity in normal-weight patients suffering from chronic schizophrenia. BMC psychiatry 14: 35. [Crossref]

14. Boneva-Asiova Z, Boyanov MA (2008) Body composition analysis by leg-to-leg bioelectrical impedance and dual-energy $\mathrm{X}$-ray absorptiometry in non-obese and obese individuals. Diabetes, Obes Metab 10: 1012-1018. [Crossref]

15. Ellis KJ (2000) Human body composition: in vivo methods. Physiol Rev 80: 649-680 [Crossref]

16. Sharpe JK, Byrne NM, Stedman TJ, Hills AP (2008) Comparison of clinical body composition methods in people taking weight inducing atypical antipsychotic medications. Asia Pac J Clin Nutr 17: 573-579. [Crossref]

17. Bigard J, Frederiksen K, Tjonneland A, Thomsen B, Overvad K, et al. (2004) Body fat and fat free mass and all-cause mortality. Obes Res 1042-1049. [Crossref]

18. Obesity: preventing and managing the global epidemic (2000). Report of a WHO consultation. World Health Organ Tech Rep Ser 894: i-xii, 1-253. [Crossref]

19. Oliveros E, Somers VK, Sochor O, Goel K, Lopez-Jimenez F (2014) The concept of normal weight obesity. Prog Cardiovasc Dis 56: 426-433. [Crossref]

20. Ruderman N, Chisholm D, Pi-Sunyer X, Schneider S (1998) The metabolically obese, normal-weight individual revisited. Diabetes 47: 699-713. [Crossref]

21. Peet M (2004) International variations in the outcome of schizophrenia and the prevalence of depression in relation to national dietary practices: an ecological analysis. The Br J Psychiatry 184: 404-408. [Crossref]

22. Amani R (2007) Is dietary pattern of schizophrenia patients different from healthy subjects? BMC Psychiatry 7: 15. [Crossref]

23. Henderson DC, Borba CP, Daley TB, Boxill R, Nguyen DD, et al. (2006) Dietary intake profile of patients with schizophrenia. Ann Clin Psychiatry 18: 99-105. [Crossref]

24. Nilsson BM, Forslund AH, Olsson RM, Hambraeus L, Wiesel FA (2006) Differences in resting energy expenditure and body composition between patients with schizophrenia and healthy controls. Acta Psychiatrica Scandinavica 114: 27-35. [Crossref]

25. Saarni SE, Saarni SI, Fogelholm M, Heliövaara M, Perälä, J, et al. (2009) Body composition in psychotic disorders: a general population survey. Psychol Med 39: 801810. [Crossref]

26. Sugawara N, Yasui-Furukori N, Tsuchimine S, Fujii A, Sato Y, et al. (2012) Body composition in patients with schizophrenia: Comparison with healthy controls. Ann Gen Psychiatry 11: 11-15. [Crossref]

27. Carr DB, Utzschneider KM, Hull RL, Kodama K, Retzlaff, et al. (2004) Intra-abdomina fat is a major determinant of the National Cholesterol Education Program Adult Treatment Panel III criteria for the metabolic syndrome. Diabetes 53: 2087-2094. [Crossref]

28. Thakore JH, Mann JN, Vlahos I, Martin A, Reznek R (2002) Increased visceral fat distribution in drug-naive and drug-free patients with schizophrenia. Int $J$ Obes Relat Metab Disord 26: 137-141. [Crossref]

29. Björntorp P (1996). The regulation of adipose tissue distribution in humans. Int J Obes Relat Metab Disord 20: 291-302. [Crossref]

30. Björntorp P (2001) Do stress reactions cause abdominal obesity and comorbidities? Obes Rev 2: 73-86. [Crossref]

31. Brönnegård M, Arner P, Hellström I, Akner G, Gustafsson JA (1990) Glucocorticoid receptor messenger ribonucleic acid in different regions of human adipose tissue. Endocrinology 127: 1689-1696. [Crossref]

32. Garaulet M, Perex-Llamas F, Fuente T, Zamora S, Tebar FJ (2000) Anthropometric, computed tomography and fat cell data in an obese population: relationship with insulin, leptin, tumor necrosis factor-alpha, sex hormone-binding globulin and sex hormones. Eur J Endocrinol 143: 657-666. [Crossref]

33. Crowther NJ, Ferris WF (2010) The impact of insulin resistance, gender, genes, glucocorticoids and ethnicity on body fat distribution. Int J Endocrinol Metab Disord 15: $115-120$.

34. Mårin P (1995) Testosterone and regional fat distribution. Obes Res 3: 609S-612S [Crossref]

35. Vogelzangs N, Kritchevsky SB, Beekman AT, Newman AB, Satterfield S, et al. (2008) Depressive symptoms and change in abdominal obesity in older persons. Arch Gen Psychiatrym 65: 1386-93. [Crossref] 
Loh SY (2017) Visceral obesity in the normal-weight people-comparing chronic schizophrenia and healthy control subjects

36. Slentz CA, Aiken LB, Houmard JA, Bales CW, Johnson JL, et al. (2005) Inactivity, exercise, and visceral fat. STRRIDE: a randomized, controlled study of exercise intensity and amount. J Appl Physiol 99: 1613-1618. [Crossref]
37. Zhang ZJ, Yao ZJ, Wen L, Qun F et al (2004) Effects of antipsychotics on fat deposition and changes in leptin and insulin levels Magnetic resonance imaging study of previously untreated people with schizophrenia. Br J Psychiatry 184: 58-62. [Crossref]

Copyright: @2017 Loh SY. This is an open-access article distributed under the terms of the Creative Commons Attribution License, which permits unrestricted use, distribution, and reproduction in any medium, provided the original author and source are credited. 